\title{
Control of mesenchymal stem cell biology by histone modifications
}

\author{
Jianhan Ren, Delan Huang, Runze Li, Weicai Wang* and Chen Zhou*
}

\begin{abstract}
Mesenchymal stem cells (MSCs) are considered the most promising seed cells for regenerative medicine because of their considerable therapeutic properties and accessibility. Fine-tuning of cell biological processes, including differentiation and senescence, is essential for achievement of the expected regenerative efficacy. Researchers have recently made great advances in understanding the spatiotemporal gene expression dynamics that occur during osteogenic, adipogenic and chondrogenic differentiation of MSCs and the intrinsic and environmental factors that affect these processes. In this context, histone modifications have been intensively studied in recent years and have already been indicated to play significant and universal roles in MSC fate determination and differentiation. In this review, we summarize recent discoveries regarding the effects of histone modifications on MSC biology. Moreover, we also provide our insights and perspectives for future applications.
\end{abstract}

Keywords: Epigenetics, Histone modifications, Mesenchymal stem cells, Cell differentiation, Cellular senescence, Cell biology

\section{Background}

Mesenchymal stem cells are multipotent cells that can differentiate into various lineages whose nomenclature remains inconsistent. Apart from "mesenchymal stem cells", MSCs are also called "mesenchymal stromal cells", "bone marrow stromal cells" (BMSCs) and "multipotent stromal cells" [1]. Friedenstein originally discovered MSCs in mouse bone marrow [2]. Since then, MSCs have been isolated from most types of mesenchymal tissue, including skeletal muscle tissue, adipose tissue, umbilical cord tissue, placenta tissue, liver tissue, skin tissue, synovial membranes, dental pulp, periodontal ligaments, cervical tissue, amniotic fluid, lung tissue, and dermal tissue [3].

According to the International Society for Cellular Therapy (ISCT) [4], MSCs must be positive for CD105, CD90, and CD73 while negative for CD45, CD34, CD14

*Correspondence: wangwc3@mail.sysu.edu.cn; zhouch46@mail.sysu.edu.cn Guanghua School of Stomatology, Hospital of Stomatology, and Guangdong Provincial Key Laboratory of Stomatology, Sun Yat-sen University, 56 Lingyuanxi Road, Guangzhou 510055, China or CD11b, CD79 $\alpha$ or CD19, and HLA class II. In addition, MSCs must be able to differentiate into osteocytes, chondrocytes and adipocytes in vitro under differentiating conditions [5]. MSCs can also transdifferentiate into different types of cells from other germ layers, including neurons, epithelial cells, cardiomyocytes, hepatic cells and islet cells [6-10], meaning that they can be used to repair or regenerate various tissues, such as cartilage, bone, and adipose tissue [11]. Moreover, MSCs possess anti-inflammatory and proinflammatory capabilities, enabling them to regulate the immune response [12-14]. MSCs are regarded as immune-privileged because they express MHC-I at low levels and are negative for MHC II and T-cell costimulatory molecules. Compared to embryonic stem cells (ESCs) and induced pluripotent stem cells (iPSCs), MSCs have low tumorigenicity [15]. These advantages make them promising candidates for the treatment of a wide range of diseases, including myocardial infarction, graft-versus-host disease (GvHD), acute respiratory distress syndrome (ARDS), amyotrophic lateral sclerosis, and chronic kidney disease, among others [16-20].

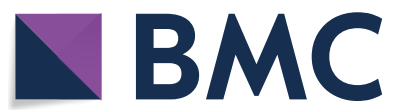

(c) The Author(s) 2020. This article is licensed under a Creative Commons Attribution 4.0 International License, which permits use, sharing, adaptation, distribution and reproduction in any medium or format, as long as you give appropriate credit to the original author(s) and the source, provide a link to the Creative Commons licence, and indicate if changes were made. The images or other third party material in this article are included in the article's Creative Commons licence, unless indicated otherwise in a credit line to the material. If material is not included in the article's Creative Commons licence and your intended use is not permitted by statutory regulation or exceeds the permitted use, you will need to obtain permission directly from the copyright holder. To view a copy of this licence, visit http://creativecommons.org/licenses/by/4.0/. The Creative Commons Public Domain Dedication waiver (http://creativecommons.org/publicdomain/zero/1.0/) applies to the data made available in this article, unless otherwise stated in a credit line to the data. 
Given the great clinical and scientific significance of MSCs, understanding of their biological characteristics in vivo and in vitro, including their proliferation, differentiation, cellular senescence and responses to abnormal microenvironments, is urgently needed. In this review, we systemically summarize the most recent progress in the field of histone modification-mediated control of MSC biological processes and our perspectives on the latest advancements.

Histone modification refers to posttranslational modification of histones. Most histone modifications involve sites within the first 30 amino acids of the $\mathrm{N}$-terminal domains of histones (also known as histone tails), such as H3K4, H3K9 and H3K27 [21]. There are many different kinds of histone modifications, including acetylation, methylation, phosphorylation, ubiquitylation, SUMOylation, and proline isomerization [22].

Histone methylation, which is mediated by histone methyltransferases (HMTs) and histone demethylases (HDMs), mainly influences lysine and arginine residues on the histone side chains; through this process, lysine can be mono-, di- or trimethylated. Different histone methylations affect gene transcription in different ways in cooperation with other identifying proteins [23-25]. Histone acetyltransferases (HATs) and histone deacetylases (HDACs) are both enzymes that regulate histone acetylation on lysine residues, but they produce opposite results $[26,27]$. In addition, proteins that contain specialized binding regions, such as bromodomains, are termed readers [28]; these proteins can recognize and bind to acetylated lysine residues, thus interacting with specific histone modifications [29].

As mentioned above, many types of histone modifications exist apart from methylation and acetylation. The major enzymes and effector molecules corresponding to these modifications are summarized in Table 1.

\section{Regulatory roles of histone modifications in MSC differentiation}

MSC differentiation is a complex process regulated by various signaling pathways with intricate crosstalk [3033 ] in which all types of epigenetic and transcriptional regulation are involved [34]. Early studies focused on how external stimuli and internal transcription factors modulate the differentiation of MSCs; however, recent studies have revealed the roles of histone modifications in this process [35]. For example, it has been well established that histones on the promoter regions of master transcription factors associated with cell fate commitment, such as $R U N X 2$ and $O S X$ in osteogenic differentiation, PPARG and CEBPA in adipogenic differentiation [36] and SOX9 in chondrogenic differentiation (Fig. 1), are dynamically modified [37]. Histone modification changes gene expression and thus strongly influences the fate commitment of MSCs. The roles of histone-modifying enzymes are described below and are summarized in Fig. 2.

\section{Roles of histone modifications in MSC osteogenic, adipogenic and chondrogenic differentiation}

Bone formation involves proliferation of MSCs, differentiation of MSCs into progenitor cells and eventually osteoblasts, and secretion of bone matrix by osteoblasts. MSC osteogenic differentiation is critical to bone formation [38], and impairment of the osteoblast differentiation potential of MSCs can lead to various diseases, such as osteoporosis, osteopetrosis, osteopenia, and oculofaciocardiodental (OFCD) syndrome [39-41]. Recent studies profiling the genome-wide patterns of different histone marks have revealed relationships between histone modifications and osteogenic differentiation of MSCs. For example, Meyer and colleagues found that the histone patterns of osteogenic differentiated MSCs are similar to those of undifferentiated MSCs by ChIP-seq and RNA-seq analyses, suggesting an intrinsic preference of MSCs for osteogenic differentiation [36]. Tan and colleagues noted that H3K9ac marks on gene promoter regions globally decrease but that $\mathrm{H} 3 \mathrm{~K} 9 \mathrm{me} 2$ marks globally increase during osteogenic differentiation through ChIP-on-chip and expression microarray analyses [42].

Adipogenesis is another important process of MSCs. Adipogenic differentiation correlates with the formation of adipose tissue, which is a critical regulator of energy homeostasis, metabolism and immunity [37]. Therefore, disruption of MSC differentiation potential results in abnormal accumulation of adipose tissue [43]. Unlike osteogenic differentiated MSCs, adipogenic differentiated MSCs have a significantly different histone pattern than undifferentiated MSCs [36].

Chondrogenesis is a critical physiological process for cartilage formation. Cartilage formation is essential not only during embryogenesis but also during bone tissue repair or the pathological processes of diseases such as osteoarthritis (OA) [44]. A previous study used genomewide ChIP and deep sequencing analyses to examine histone mark changes in specific genes during chondrogenic differentiation [45]. The active marks H3K4me3, H3K9ac and H3K36me3 were enriched on upregulated chondrogenic signature genes, including COL2A1, COL9A2, and $A C A N$, among others, whereas the levels of the repressive mark H3K27me3 were decreased on these genes. In contrast, H3K4me3, H3K9ac and H3K36me3 levels were decreased, while H3K27me3 levels were slightly increased, on the genes associated with MSC traits, such as CXCL12 [46]. 
Table 1 Major histone modification writers, erasers and readers

\begin{tabular}{|c|c|c|c|}
\hline Type & Major member & Modification/identification site & Function \\
\hline \multicolumn{4}{|l|}{ Writers } \\
\hline \multirow[t]{3}{*}{ Histone acetylation } & GCN5 & H3K9, H3K14, H3K18, H3K36, H4K8 & Transcriptional activation \\
\hline & p300/CBP & $\begin{array}{l}\text { H2AK5 } \\
\text { H3K18, H3K27 } \\
\text { H4K8, H4K12 }\end{array}$ & Transcriptional activation \\
\hline & Tip60 & $\begin{array}{l}\text { H2AK5 } \\
\text { H3K14 } \\
\text { H4K5, H4K8, H4K12, H4K16 }\end{array}$ & Transcriptional activation \\
\hline \multirow[t]{6}{*}{ Histone methylation } & $\begin{array}{l}\text { SUV39h1 } \\
\text { SUV39h2 }\end{array}$ & H3K9 & Transcriptional silencing \\
\hline & G9a & H3K9 & Transcriptional repression \\
\hline & SETDB1 & H3K9 & Transcriptional repression \\
\hline & $\mathrm{EZH} 2$ & $\mathrm{H} 3 \mathrm{~K} 27$ & Transcriptional silencing \\
\hline & SETD2 & H3K36 & Transcriptional elongation \\
\hline & CARM1 & H3R17, H3R26, H3R42 & Transcriptional activation \\
\hline Histone phosphorylation & Aurora B & $\mathrm{H} 3 \mathrm{~S} 10, \mathrm{H} 3 \mathrm{~S} 28$ & Transcriptional activation \\
\hline \multirow[t]{2}{*}{ Histone ubiquitylation } & Ring1B & $\mathrm{H} 2 \mathrm{~A}$ & Transcriptional repression \\
\hline & Rad6 & $\mathrm{H} 2 \mathrm{~B}$ & Transcriptional elongation \\
\hline \multicolumn{4}{|l|}{ Erasers } \\
\hline \multirow[t]{4}{*}{ Histone methylation } & LSD1 & $\mathrm{H} 3 \mathrm{~K} 4, \mathrm{H} 3 \mathrm{~K} 9$ & Transcriptional activation/repression \\
\hline & KDM4B & H3K9 & Transcriptional activation \\
\hline & KDM6B & $\mathrm{H} 3 \mathrm{~K} 27$ & Transcriptional activation \\
\hline & JMJD1C & $\mathrm{H} 3 \mathrm{~K} 9$ & Transcriptional activation \\
\hline \multirow[t]{4}{*}{ Histone acetylation } & HDAC1 & $\mathrm{H} 2 \mathrm{~A}, \mathrm{H} 2 \mathrm{~B}, \mathrm{H} 3, \mathrm{H} 4$ & Transcriptional repression \\
\hline & HDAC4 & $\mathrm{H} 2 \mathrm{~A}, \mathrm{H} 2 \mathrm{~B}, \mathrm{H} 3, \mathrm{H} 4$ & Transcriptional repression \\
\hline & HDAC6 & $\mathrm{H} 2 \mathrm{~A}, \mathrm{H} 2 \mathrm{~B}, \mathrm{H} 3, \mathrm{H} 4$ & Transcriptional repression \\
\hline & HDAC8 & $\mathrm{H} 2 \mathrm{~A}, \mathrm{H} 2 \mathrm{~B}, \mathrm{H} 3, \mathrm{H} 4$ & Transcriptional repression \\
\hline Histone phosphorylation & PP1 & $\mathrm{H} 3 \mathrm{~S} 10, \mathrm{H} 3 \mathrm{~S} 28$ & Transcriptional repression \\
\hline Histone ubiquitylation & Ubp8 & $\mathrm{H} 2 \mathrm{~B}$ & Transcriptional activation \\
\hline \multicolumn{4}{|l|}{ Readers } \\
\hline Acetyl-lysine binding domains & BRD2 & Acetylated lysine & Chromatin remodeling \\
\hline Methyl-lysine binding domains & $\begin{array}{l}\text { Brpf1 } \\
\text { HP1 } \\
\text { L3MBTL1 }\end{array}$ & Methylated lysine & \\
\hline
\end{tabular}

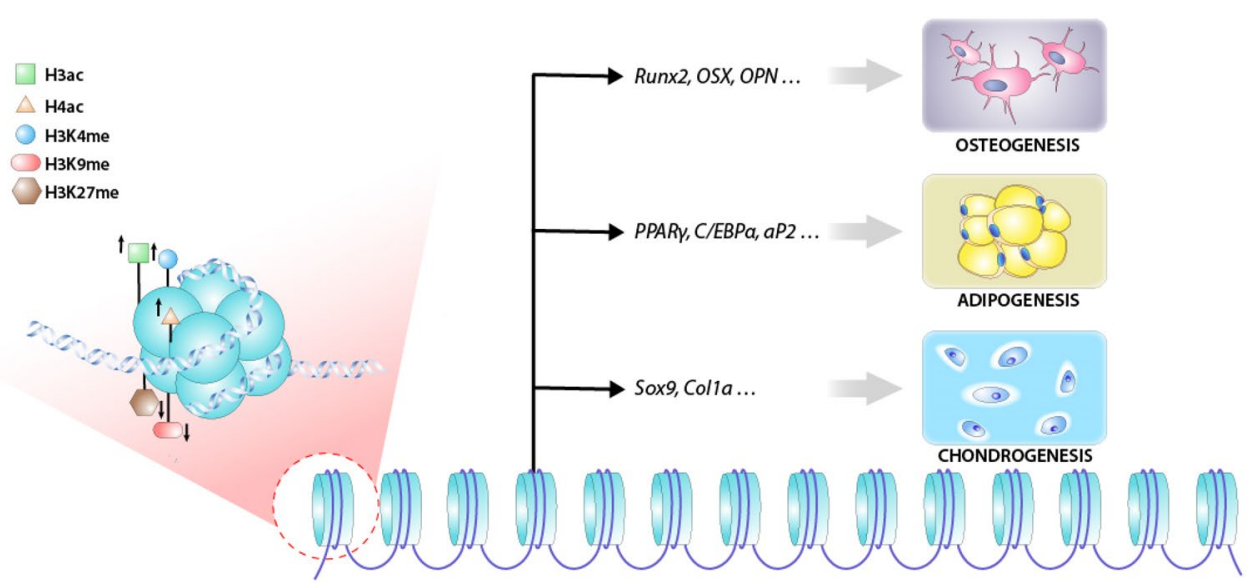

Fig. 1 MSC fate determination is associated with histone modifications on specific regions of lineage-specific genes 

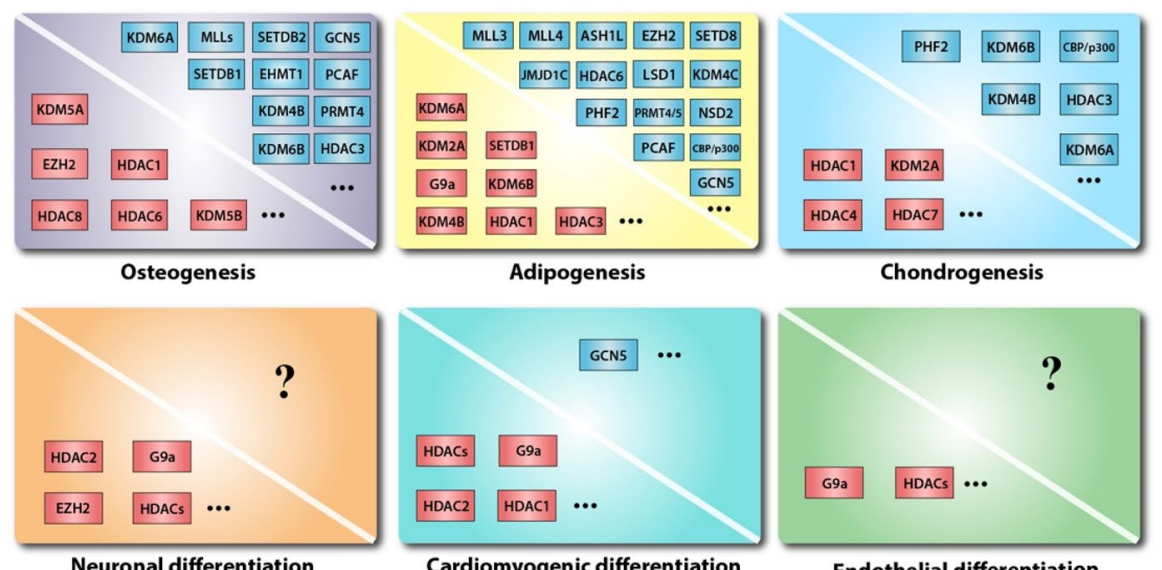

Endothelial differentiation

Fig. 2 The various roles of histone-modifying enzymes in determining different MSC fates

To further clarify the exact roles of histone modifications in these various MSC processes, we will discuss how specific histone marks and histone-modifying enzymes impact the differentiation of MSCs.

\section{H3K4 methylation}

Methylation of H3K4 is associated with an active or poised transcription state and is found in the promoters of most genes [47-49]. Some previous studies have implied that H3K4me3 levels may be associated with osteogenesis. An initial study reported that depletion of Hoxa10, a BMP2-inducible gene, impairs osteogenesis by decreasing H3K4 methylation [50]. Consistent with this report, some HDMs that specifically demethylate H3K4 have been identified to directly influence MSC osteogenic differentiation. In addition, recent studies have proven the negative effects of the HDMs KDM5A and KDM5B on the osteogenic differentiation of MSCs [51, 52]. Knockdown of KDM5A or KDM5B increases H3K4me3 levels in the promoter region of Runx2 and results in upregulation of osteogenic differentiation. Odontoblasts are cells that secrete dentin during tooth development. These cells differentiate from MSCs under the control of various signaling pathways, including the Wnt, Bmp, Shh and Notch pathways [53-55]. Zhou and colleagues recently found that mixed lineage leukemias (MLLs, H3K4me3 methylases) and KDM6A/B (H3K27me3 demethylases) play essential roles in the expression of $W n t 5 a$, a member of the Wnt ligand family, as well as in odontogenic differentiation [56].

In addition to the promoters of genes associated with osteogenesis, those of adipose tissue-specific genes such as apM1 exhibit increased H3K4me3 levels in MSCs during adipogenic differentiation [57]. The H3K4 methyltransferases MLL3 and MLL4 are components of the
ASC-2 complex (ASCOM), which acts as a transcriptional coactivator of PPAR $\gamma$ and C/EBP $\alpha$. Mice expressing inactivated MLL3 or MLL4 have less fat than mice expressing the activated versions of these proteins, and mouse embryonic fibroblasts isolated from the inactivated MLL3/MLL4-expressing mice exhibit lower adipogenic differentiation potential, suggesting the positive roles of MLL3 and MLL4 in adipogenesis [58]. A recent study also reported that silencing of Ash1l, an H3K4 methyltransferase, promotes adipogenesis while suppressing osteogenesis and chondrogenesis by affecting certain master transcription factors. Intriguingly, both ASH1L and H3K4me3 are present at the transcription start sites (TSSs) of Osx, Runx2 and Sox9, whereas only H3K4me3 is present at the TSS of Pparg. Therefore, silencing of Ash1l downregulates H3K4me3 levels on the Osx and Runx 2 promoters but not on the Pparg promoter, consistent with the impact of Ash $1 l$ silencing on differentiation [59]. Furthermore, knockdown of KDM2A upregulates SOX2 and NANOG expression by increasing H3K4me3 on the promoters of these genes and thus enhances both adipogenic and chondrogenic differentiation potential in human stem cells from the apical papilla (SCAPs) [60].

\section{H3K9 methylation}

H3K9 dimethylation and trimethylation are both repressive histone modifications and are mainly catalyzed by G9a/GLP and SUV39H1/2, respectively, mediating the formation of heterochromatic regions through interaction with HP1 [61, 62]. Knockdown of ESET or SETDB1, a H3K9 methyltransferase, causes bone defects in mice [63]. Mechanistically, the impairment of osteogenic differentiation results from histone methylationinduced aberrant expression of Runx2. Euchromatin 
HMT1 (EHMT1), also known as G9a-like protein (GLP), specifically dimethylates H3K9. Balemans and colleagues reported that knockdown of EHMT1 decreases H3K9me2 levels on the promoters of Runx2 and Col22a1 and thereby upregulates the transcription of these genes in brain and bone tissues. Although the authors did not provide direct evidence that EHMT1 regulates the osteogenic differentiation of MSCs, they found a severe type of craniofacial bone malformation, Kleefstra syndrome, in $E h m t^{+/-}$mice [64]. In addition to HMTs, the HDM KDM4B plays a critical role in the osteogenic differentiation of MSCs by removing H3K9me3 [65]. Knockdown of KDM4B increases H3K9me3 on the promoters of several osteogenic genes and ultimately reduces osteogenic differentiation. Furthermore, a similar phenomenon has been observed in osteoporotic and aging mice, which may indicate a possible relationship between H3K9me3 and osteoporosis/senescence.

With regard to adipogenic differentiation of MSCs, G9a, an HMT that specifically methylates H3K9me1 and H3K9me2, has been proven to regulate PPAR $\gamma$ expression through enrichment of H3K9me2 on Pparg promoter regions and the treatment with BIX01294 (a G9a inhibitor) thereby promotes PPAR $\gamma$ expression and adipogenic differentiation [66]. In addition, the H3K9 demethylase PHF2 physically interacts with C/EBP $\alpha$ and C/EBP $\delta$ and binds to the Pparg and Fabp4 promoters, ultimately promoting adipogenic differentiation by lowering the H3K9 methylation levels in these regions [67]. Inhibition of KDM4C, another H3K9 demethylase, with 2-hydroxyglutarate produced by mutating isocitrate dehydrogenase 1 (IDH1) blocks adipogenic differentiation [68]. Moreover, a recent report demonstrated that depletion of $J M J D 1 C$ increases H3K9me2 levels on the C/EBP and PPARG promoters and suppresses adipogenesis by decreasing the expression of these master transcription factor genes [69]. Knockdown of SETDB1 also promotes adipogenesis through downregulation of H3K9me2 and upregulation of H3K4me2 on the Cebpa promoter [70]. Another study reported the existence of H3K4/H3K9me3 bivalent chromatin domains in the Cebpa promoter region and examined their regulatory effects on gene expression and adipogenesis. These H3K4/H3K9me3 bivalent chromatin domains are induced by DNA methylation and SETDB1 recruitment [71]. Similar to these domains, LSD1 also regulates H3K9me2 and H3K4me2 levels on the Cebpa promoter as well as on Wnt pathway gene promoters and promotes adipogenic differentiation by facilitating $\mathrm{C} /$ EBP $\alpha$ expression and inhibiting the Wnt signaling pathway $[70,72]$.

Research on AT-rich interactive domain 5b (Arid5b), a transcriptional coregulator of Sox9, has shown that this molecule promotes chondrogenic differentiation by recruiting the H3K9 demethylase PHF2 to the promoters of the Sox 9 target genes Col2a1 and Aggrecan, thereby decreasing H3K9me2 levels in these regions [63]. Moreover, another HDM, KDM4B, removes H3K9me3 marks on the promoter region of Sox9 and thus upregulates SOX9 expression [73]. Accordingly, depletion of KDM4B inhibits chondrogenic differentiation, while overexpression of KDM4B promotes chondrogenic differentiation.

\section{H3K27 methylation}

H3K27 methylation is another heterochromatic histone modification associated with transcriptional repression [74-76]. Wu and colleagues found that H3K27me3 levels are significantly reduced in the promoter regions of all transcriptionally upregulated genes during the process of osteogenesis [77]. Polycomb group (PcG) proteins, which were first identified 40 years ago, form PRC transcription-repressing complexes and are responsible for methylation of H3K27 [78]. Enhancer of zeste 2 (EZH2), a component of PRC2, increases H3K27me3 on the promoters of Wnt genes, including Wnt1, Wnt6, $W n t 10 a$, and Wnt10b [79], suggesting a potential role of EZH2 in osteogenesis. Furthermore, knockdown of CDK-1, which phosphorylates EZH2 at T487, significantly increases EZH2 and H3K27me3 on the Runx2 and Tcf7 promoters [80]. Similar to knockdown of KDM4B, knockdown of KDM6B also attenuates osteogenesis by catalyzing H3K27me3 modification of osteogenic genes [65]. In addition, Hemming and colleagues demonstrated that KDM6A and EZH2 act as epigenetic switches regulating MSC differentiation. KDM6A and EZH2 regulate H3K27me3 status on the promoters of both osteogenic and adipogenic genes, including Runx2, Oc, Pparg and Cebpa, and knockdown of EZH2 or overexpression of KDM6A promotes osteogenesis [81]. A recent study further explored the roles of other novel EZH2-targeted genes in osteogenic differentiation and found that EZH2 binds to the TSS regions of FHL1 and the osteogenesis regulators $Z B T B 16$ and $M X 1$ and establishes H3K27me3 modifications. Overexpression of EZH2 decreases the expression of these genes, which downregulates RUNX2, $O P N$ and $O C$ (Osteocalcin) [82].

EZH2 and KDM6A exhibit different regulatory functions in adipogenesis than in osteogenesis; a previous study revealed that overexpression of EZH2 or knockdown of KDM6A promotes adipogenic differentiation of MSCs [81]. However, this study did not elucidate the direct regulatory effects of EZH2/KDM6A or H3K27me3 modifications on adipogenesis-specific genes. A recent study showed that phosphorylation of $\mathrm{H} 2 \mathrm{~B}$ recruits EZH2 and initiates adipogenesis [83] through a mechanism involving increases in H3K27me3 levels at the 
promoters of Wnt genes and subsequent repression of Wnt gene expression.

In addition to affecting osteogenesis and adipogenesis, the H3K27me3 demethylases KDM6A and KDM6B have also been reported to facilitate the chondrogenic differentiation of MSCs [84-87]. A study on $K d m 6 b^{-1-}$ mice showed that KDM6B is recruited to the promoter of Runx2, a critical regulator of chondrocyte maturation and endochondral bone formation, and Ihh and activates the expression of these genes by decreasing the levels of repressive H3K27me3 marks [85]. Another study demonstrated that GSK-J4, an inhibitor of KDM6B and KDM6A, inhibits SOX9 and COL2A1 expression and thereby disrupts chondrogenic differentiation [84]. A further study showed that knockdown of KDM6A reduces H3K27me3 levels but increases H3K4me3 levels in the promoter regions of Sox 9 and therefore inhibits chondrogenic differentiation through repression of SOX9 expression. These results suggest that both KDM6A and KDM6B play essential roles in the entire process of chondrogenesis, from the initial stage of differentiation to the maturation of chondrocytes.

\section{Other types of histone methylation}

H3K36me3 is a histone mark that triggers transcription elongation [49]. SETD2, an HMT specifically catalyzing $\mathrm{H} 3 \mathrm{~K} 36 \mathrm{me}$, is responsible for MSC osteogenic differentiation, and conditional depletion of Setd2 in Prx1-Cre mice decreases bone formation. RNA-seq and ChIP-seq analyses have shown that loss of Setd2 results in downregulation of H3K36me3 levels on the $L b p$ gene and impairs the transcriptional initiation and elongation of this gene [88]. In addition, $\mathrm{Lu}$ and Colleagues demonstrated that the H3K36 mutations $\mathrm{K} 36 \mathrm{M}$ and K36I impair MSC differentiation into chondrocytes and induce the formation of undifferentiated sarcoma [89]. Genome-wide profiling of H3K36me2/3 and H3K27me3 has shown that these mutations downregulate H3K36 methylation and lead to redistribution of the H3K27me3 landscape. The H3K36 mutation causes H3K27me3 to become enriched in intergenic regions and relatively scarce in genic regions, facilitating the expression of genes blocking mesenchymal differentiation. In addition to chondrogenic differentiation, knockout (KO) of the H3K36 methyltransferase Nsd2 has also been reported to impair adipogenic differentiation of MSCs by inhibiting PPAR $\gamma$ target gene expression [90].

The impact of H4K20 methylation on gene transcription is intriguing. H4K20 monomethylation is found in euchromatic regions and is associated with active transcription, while H4K20 dimethylation and trimethylation are more related to transcriptional repression and chromatin compaction [91-93]. SETD8, an HMT that specifically monomethylates $\mathrm{H} 4 \mathrm{~K} 20$, has been shown to participate in a positive feedback loop. SETD8 is upregulated by PPAR $\gamma$ during adipogenic differentiation, whereas SETD8 inversely modulates PPARY expression through H4K20 monomethylation and thus promotes adipogenic differentiation of MSCs [94].

In addition to those on lysine residues, histone modifications on arginine residues also influence MSC differentiation. Coactivator-associated arginine methyltransferase 1 (CARM1), a protein arginine methyltransferase (PRMT) also known as PRMT4, targets histone H3 asymmetric methylation on arginine residues 17, 26 and 42 [95, 96]. Delivery of CARM1 into MSC nuclei using cell-penetrating peptides (CPPs) strongly increases the expression of pluripotent marker genes, including Oct4, Sox2, and Nanog, through upregulation of H3R17me2 levels on their promoter regions. In addition, CPPCARM1 treatment enhances osteogenic, adipogenic and myogenic potential [95]. With regard to adipogenesis, another study has verified that CARM1 promotes adipogenic differentiation through coactivation with PPAR $\gamma$ [97]. CARM1 and PPAR $\gamma$ bind to the promoter region of $a P 2$, an adipogenic gene, and induce $a P 2$ expression by upregulating H3R17 methylation [97]. PRMT5, another PRMT that mainly methylates H3R2, H3R8 and H2A/ H4R3, has also been demonstrated to promote adipogenesis by upregulating adipogenic genes. Mechanistically, PRMT5 increases H3R8me2 levels on the adiponectin, resistin, and $a P 2$ promoters in $\mathrm{C} 3 \mathrm{H} 10 \mathrm{~T} 1 / 2$ cells and then facilitates the expression of these genes via recruitment of BRG1, an ATPase subunit of SWI/SNF chromatinremodeling enzymes [98].

\section{Histone acetylation}

HATs and HDACs are both essential for osteogenic differentiation. PCAF, an H3K9 acetyltransferase also known as KAT2B, is recruited to the promoters of $B m p 2$, Bmp3, Bmpr1b and Runx2, and knockdown of PCAF significantly impairs osteogenic differentiation of MSCs. In addition, osteoporotic mice show lower expression of PCAF in bone tissue than control mice [18]. GCN5, a paralog of PCAF also known as KAT2A, also contributes to osteogenesis. A recent study revealed that GCN5 binds to the promoters of Wnt1, Wnt6, Wnt10a, and Wnt10b and increases the expression of these genes through upregulation of H3K9ac levels. This activation of Wnt signaling results in enhanced osteogenesis [99]. Notably, some HATs function in a histone-independent way, regulating differentiation-related gene expression in MSCs and thereby fate commitment of MSCs through direct interaction with other non-histone proteins [100-103]. Several pan-HDAC inhibitors have also been reported to upregulate the osteogenic potential of MSCs [104-106], 
indicating the significant roles of HDACs in osteogenic differentiation. Furthermore, several studies have demonstrated the function of HDAC6 in the differentiation process [107-109]. The expression of HDAC6 is reduced during osteogenic differentiation, and HDAC6 negatively regulates the expression of $O C, O p n, B s p 2$, Osx, and $A L P$ partly by binding to the Runx2 C-terminus and adjusting Runx2 activity. HDAC1 also affects osteogenic differentiation. Lee and colleagues reported that HDAC1 recruitment to the promoters of Osx and $O C$ is reduced during osteogenesis of mouse BMSCs, leading to upregulation of H3K9 and H4 acetylation [110]. Furthermore, mechanical stimulation has been proven to affect the fate commitment of MSCs [111]. Wang and colleagues demonstrated that downregulation of HDAC1 during cyclic mechanical stretch (CMS)-induced osteogenic differentiation attenuates Notch signaling by inducing $\mathrm{H} 3$ acetylation on the promoter of JAG1 [112]. In addition, the expression of Colla1 and Runx 2 has recently been shown to be decreased in chondrogenic cells from Hdac3-CKOPrrx 1 mice in osteoinductive culture, indicating a supportive role of HDAC3 in osteogenic differentiation [113]. Another recent study found that upregulation of HDAC8 in fibrous dysplasia is associated with impaired osteogenesis, while HDAC8 inhibition promotes osteogenic differentiation of MSCs [114].

Depletion of $\mathrm{CBP} / \mathrm{p} 300$ with ribozyme strongly represses the expression of PPAR $\gamma$-targeted genes and thus attenuates adipogenic differentiation of preadipocytes [115]. Furthermore, studies on the mechanism of p300-mediated histone modification have revealed that p300 binds to Pparg2 promoter and enhancer regions with enhanced $\mathrm{H} 3 / \mathrm{H} 4 \mathrm{ac}$ and $\mathrm{H} 3 \mathrm{~K} 27 \mathrm{ac}$, respectively [116, 117]. GCN5 and PCAF have also been reported to be involved in MSC adipogenic differentiation. These factors are recruited to Pparg2 and Prdm16 promoters and increase the H3K9ac levels on the sites. Depletion of both Gcn5 and PCAF suppresses adipogenic differentiation of mice preadipocytes [118]. Yoo and colleagues [119] investigated the roles of HDACs in adipogenic differentiation and found that HDAC1, HDAC2 and HDAC5 are downregulated during adipogenic differentiation. Moreover, treatment with sodium butyrate $(\mathrm{NaBu})$, a nonspecific HDAC inhibitor, promotes adipogenesis. The role of HDAC9 in adipogenic differentiation has been explored with $H d a c 9-K O$ transgenic mice [120]; such studies have revealed that HDAC9 is recruited to the Cebpa promoter along with USF1 and p300 and that KO of Hdac9 promotes adipogenic differentiation of preadipocytes. However, a study on HDAC9 lacking the deacetylase domain showed that this effect of HDAC9 occurs through a deacetylase-independent mechanism. Although negative roles of HDACs in adipogenesis have been reported,
Huang and colleagues proposed that HDAC6 facilitates adipogenic differentiation [108]. Their study revealed that inhibition of Hdac6 with miR-22 represses adipogenic differentiation and relevant transcription factor expression but promotes osteogenic differentiation.

Tsuda and colleagues first reported the positive function of $\mathrm{CBP} / \mathrm{p} 300$ in chondrogenesis [121], finding that $\mathrm{CBP} / \mathrm{p} 300$ binds to Col2a1 promoter regions in an interaction with Sox 9 and promotes Col2al expression as well as chondrogenesis. Another study revealed that p300 promotes Col2a1 expression and chondrogenesis by increasing the histone acetylation levels of the Col2a1 gene [122]. HDACs have also been reported to affect chondrogenic differentiation. For example, a study on the transcriptional regulation of cartilage oligomeric matrix protein (COMP), a marker gene for chondrogenesis, revealed a repressive role of HDAC1 in chondrogenic differentiation [123], demonstrating that leukemia/lymphoma-related factor (LRF) recruits HDAC1 to the negative regulatory element (NRE) of the COMP promoter and downregulates COMP expression. The inhibitory effect of the LRF-HDAC1 complex can be attenuated by application of Trichostatin A (TSA), indicating the critical role of HDAC1 in chondrogenesis. HDAC1 has also been reported to bind to the promoter of $\beta$-catenin and to suppress $\beta$-catenin expression, playing a negative role in chondrogenesis [124]. Similarly, HDAC4 functions negatively in chondrogenic differentiation [125]. Overexpression of HDAC4 attenuates chondrocyte hypertrophy and endochondral bone formation by inhibiting the activity of RUNX2, a regulator of chondrocyte hypertrophy. Hdac4-deficient mice show a phenotype with ectopic and early-onset chondrocyte hypertrophy, indicating upregulation of chondrogenic potential. In contrast, positive chondrogenic effects of the HDACs HDAC7 and HDAC3 have been identified by Bradley and colleagues [126, 127]. Depletion of $H d a c 7$ promotes chondrogenesis through upregulation of $\beta$-catenin. In addition, HDAC3 is recruited to the promoter of Phlpp1, a component regulating Akt signaling, and promotes chondrogenesis by repressing Phlpp1 expression and upregulating Akt signaling. However, HDAC7 is highly expressed in proliferating chondrocytes, while HDAC3 is highly expressed in prehypertrophic chondrocytes, suggesting that different HDACs exert various functions at different stages of chondrogenesis.

\section{Roles of histone modifications in MSC transdifferentiation into other lineages}

In addition to osteogenic, adipogenic and chondrogenic lineages, highly plastic and multipotent MSCs from different germ layers can differentiate into other cell lineages, such as neuron, epithelial cell, cardiomyocyte, 
hepatocyte and islet cell lineages, under certain induction culture conditions. Although the exact mechanism of transdifferentiation is largely unknown, epigenetic regulation has been reported to be critical in the process [3, 34]. In the next section, we discuss how histone modifications regulate the transdifferentiation of MSCs.

\section{Neuronal differentiation}

EZH2 is recruited to the promoter of PIP5K1C, a neuron-related gene regulating $\mathrm{Ca}^{2+}$ signaling, and downregulates PIP5K1C expression. Accordingly, knockdown of EZH2 promotes the neuronal differentiation of MSCs through activation of PIP5K1C-mediated $\mathrm{Ca}^{2+}$ signaling [128]. The G9a inhibitor BIX-01294 has been reported to promote neuronal differentiation. Mechanistically, BIX-01294 induces the expression of neuronal-specific genes, including Nestin, Musashi, CD133 and GFAP, by downregulating $G 9 a$ as well as H3K9me2 levels at repressor element-1 (RE-1) of these genes [129]. In addition to histone methylation, histone acetylation has also been shown to affect neuronal differentiation; the HDAC inhibitor valproic acid (VPA) facilitates MSC neuronal differentiation by upregulating neuronal-specific genes [10]. These results have been further validated with human placenta-derived MSCs and have been proven to be mediated by inhibition of HDAC2 [130]. Recently, HDAC inhibitors including MS-275, NaBu, TSA, and VPA were reported to promote neuronal differentiation of MSCs through activation of the Wnt signaling pathway [131].

\section{Cardiomyogenic differentiation}

Suberoylanilide hydroxamic acid (SAHA), an HDAC inhibitor, is much more powerful than 5-azacytidine, a DNA methylation inhibitor, in inducing the expression of the early cardiomyocyte-specific genes GATA4 and $N k \times 2.5$, indicating that histone acetylation levels are possibly more vital than DNA methylation levels during cardiomyogenic differentiation [132]. GCN5 plays a favorable role in cardiomyogenic differentiation [133, 134]. GCN5 induces $\mathrm{H} 3$ acetylation on the promoters of GATA4 and $N k \times 2.5$ and enhances the expression of these genes under cardiomyogenic induction conditions [133]. In addition, knockdown of HDAC1 facilitates the expression of the cardiac-specific genes GATA4, Nkx2.5, CTnT, and $M H C$, thereby promoting cardiomyogenic differentiation [135]. These findings have also been validated by Wang and colleagues [9], who demonstrated that knockdown of HDAC1 or Hdac2 enhances the expression of the cardiomyocyte-specific genes Myh6 and Tnni3 through upregulation of both $\mathrm{H} 3$ and $\mathrm{H} 4$ acetylation levels on the corresponding promoters.

\section{Endothelial differentiation}

In addition to cardiomyogenic differentiation, HDAC inhibitors can also promote hepatic differentiation of MSCs [136, 137]. Snykers and colleagues revealed that TSA supplementation greatly enhances hepatic differentiation induced by hepatogenic factors [136]. The resulting differentiated cells exhibit epithelial morphology, hepatic gene expression and hepatocyte functions. In addition, VPA promotes hepatic differentiation of MSCs by upregulating global $\mathrm{H} 3 / \mathrm{H} 4$ acetylation levels [138]. In addition to hepatic lineage cells, MSCs can transdifferentiate into cells of another endoderm cell lineage: endothelial cells. Inhibition of G9a with BIX-01294 promotes endothelial differentiation of human adipose-derived MSCs by enhancing the expression of some endothelial markers and blood vessel formation factors [139].

\section{Roles of histone modifications in MSC senescence}

The numbers of MSCs isolated from tissues are usually insufficient to meet clinical needs. Therefore, these primary MSCs are usually expanded in vitro. However, in vitro culture changes the morphology and reduces the differentiation potential and proliferation ability of late-passage MSCs, while in vivo senescence disrupts tissue homeostasis and eventually leads to aging-related diseases [140, 141]. Mechanistically, various cell biological processes contribute to the senescence of MSCs, including telomere- and telomerase-related processes, epigenetic changes, gene expression changes and immunological processes [142]. Among the alterations, alterations in histone modification patterns have been shown to be associated with senescence in studies on different species and cell lineages [143]. Correlations between histone modifications and DNA methylation in the context of MSC senescence are elucidated by a genome-wide study [144]. The results show that DNA-methylated genes display certain tendencies toward hyper- or hypomethylation during aging. In addition, hypermethylation is associated with the repressive histone marks H3K9me3 and H3K27me3, while hypomethylation is associated with H3K4me1.

During cellular senescence, the repressive histone modification H3K27me3 is downregulated, indicating its vital role in aging $[145,146]$. Recently, Li and colleagues demonstrated that deletion of $E z h 2$ results in premature senescence of MSCs in a study on Ezh2-CKO ${ }_{\text {Nestin }}$ transgenic mice [147]. Aged MSCs, marked with a Nestin$\mathrm{GFP}^{-}$signature, express much less EZH2 than control MSCs. Downregulation of Ezh2 decreases H3K27me3 marks on the promoters of $p 15^{I N K 4 b}, p 16^{I N K 4 a}$, the cell cycle inhibitor genes $p 21^{C I P 1}$ and $p 27^{K I P 1}$ and facilitates the expression of these genes. Furthermore, $\mathrm{KO}$ of Ezh2 
increases the percentage of SA- $\beta \mathrm{Gal}^{+}$cells, directly indicating that cellular senescence is upregulated.

Another HMT, SUV39H1, which specifically targets H3K9me3, also functions in MSC senescence [148]. One study on a premature aging model demonstrated that KO of WRN in MSCs decreases H3K9me3 on $\alpha$ Sat and Sat2 loci and upregulates the transcription of these genes. Knockdown of SUV39H1 or HP1 $\alpha$, a cofactor of SUV39H1, results in downregulation of global H3K9me3 levels and MSC senescence, while overexpression of HP1 $\alpha$ upregulates H3K9me3 levels and therefore represses MSC senescence. Similarly, MSCs with catalytically inactivated endogenous SUV39H1 exhibit the same phenotype of accelerated cellular senescence, indicating that histone modifications induced by SUV39H1 and HP1 $\alpha$ play significant roles in MSC senescence.

With regard to histone acetylation, $\mathrm{Li}$ and colleagues found that the expression of RUNX2 and ALP increases in MSCs during aging, whereas that of the stemness markers OCT4 and SOX2 decreases. These alterations in gene expression result from dysregulation of H3K9ac and H3K14ac marks in the promoter regions of these genes, while methylation of CpG islands appears to remain unchanged [149]. As observed in previous studies [150-152], aging MSCs progressively lose their proliferation and differentiation potential, although osteogenic ability is attenuated more rapidly than adipogenic ability. A recent study revealed that the levels of the H3K9 acetyltransferase PCAF are significantly decreased in aged mice, which increases adipogenesis and decreases osteogenesis. Reducing PCAF in aged mice represses the expression of some osteogenic genes through downregulation of H3K9ac levels on these genes [18]. In contrast, another study on changes in adipogenic potential in aged MSCs demonstrated that recruitment of BMI1 and EZH2 to the promoters of adipocyte-specific genes results in high H3K27me3 levels, repressing the expression of these genes and therefore inhibiting adipogenic differentiation [153].

HDACs seem to exert various influences on MSC senescence. One study found that MSC senescence decreases the expression of HDAC1 and HDAC2. HDAC1 and HDAC2 upregulate the expression of HMT PcGs such as BMI1, EZH2 and SUZ12 through RB phosphorylation while downregulating the expression of KDM6B through direct promotion of $\mathrm{H} 3$ acetylation on the KDM6B promoter [154]. As a result, inhibition of HDAC1 and HDAC2 with specific siRNAs decreases PcG expression and increases KDM6B expression, reducing the levels of repressive H3K27me3 marks on the $p 16^{I N K 4 A}$ promoter and initiating expression of this gene [154]. In contrast, Zhu and colleagues found that HDAC4, HDAC5 and HDAC6 are increased during MSC senescence. This change is associated with decreases in global $\mathrm{H} 3$ and H4 acetylation levels and OCT4 expression [155]. The HDAC inhibitors TSA and largazole enhance the expression of some pluripotent and proliferative genes through upregulation of $\mathrm{H} 3 \mathrm{~K} 9 \mathrm{ac}$ and $\mathrm{H} 3 \mathrm{~K} 14 \mathrm{ac}$ and therefore delay the senescence of MSCs [156]. However, $\mathrm{NaBu}$, VPA and MS-275 enhance MSC senescence [154, 157]. The conflicting effects of these pan-HDAC inhibitors on MSC senescence may be due to different effects on different HDACs.

\section{Roles of histone modifications in other MSC biological processes}

The therapeutic potential of MSCs is associated with their paracrine effects [158], and regulation of the HAT GCN5 could amplify angiogenesis during MSC therapy [159]. In osteoporosis mice, decreases in GCN5 are associated with impairment of the proangiogenic capacity of BMSCs. Mechanistically, GCN5 binds to the promoter of Vegf and increases H3K9ac levels, which facilitates VEGF expression and therefore enhances angiogenesis. Shen and colleagues found that the lncRNA H19 affects angiogenesis of human amniotic MSCs (HAMSCs) in an EZH2-dependent manner [160]. Knockdown of H19 in HAMSCs inhibits the formation of vessel-like structures when HAMSCs and human umbilical vein endothelial cells (HUVECs) are injected subcutaneously into nude mice. Mechanistically, H19 interacts with EZH2, facilitating its binding to the promoter region of VASH1, an angiogenesis inhibitor gene, and therefore suppresses VASH1 expression by increasing H3K27me3 levels.

Efforts have been made to promote the therapeutic effects of MSCs through genetic modification and pretreatment (priming) before MSC administration [161-164]. For example, treatment with combinations of DNA-hypomethylating agents and HDAC inhibitors has recently been shown to enhance the anti-inflammatory effects of MSCs [165]. Such epigenetically modified MSCs express increased levels of IL-10 and IDO and inhibit $\mathrm{T}$ cell differentiation of peripheral blood mononuclear cells (PBMCs) under T0 and T17 conditions. These MSCs also suppress the expression of proinflammatory factors, including IL-17, IFN- $\gamma$ and IL-2, when cultured with PBMCs. Furthermore, coculture of epigenetically modified MSCs with synovial fluid mononuclear cells (SFMCs) from rheumatoid arthritis patients decreases $\mathrm{IL}-17^{+} / \mathrm{CD} 4^{+} \mathrm{T}$ cell populations and downregulates IL-17 and IL-2 expression. Sphingosine-1 phosphate (S1P) is used as a priming factor in MSC therapy to enhance MSC function; however, S1P exhibits low efficacy and can induce adverse inflammatory reactions in vivo [166]. A recent study has reported that the HDAC inhibitor VPA can cooperate with S1P to increase CXCR4 
expression in MSCs and to enhance MSC migration, selfrenewal and anti-inflammatory capabilities [167].

Furthermore, HDAC1 silencing in human umbilical cord-derived MSCs (hUC-MSCs) enhances the neuroprotective effects of these cells against traumatic brain injury (TBI) in mice [168]. Knockdown of HDAC1 in hUC-MSCs enhances cell viability and attenuates oxidative stress, neuroinflammation and cell death after TBI through modulation of the PI3K/AKT pathway. However, how HDAC1 regulates PI3K/AKT on the chromatin level remains unclear.

\section{Conclusion}

Through this discussion of various fruitful studies, we have provided a brief overview of the roles of histone modifications in MSC biology. Modulation of histonemodifying enzymes is likely a promising strategy for regulation of MSC differentiation and senescence.

However, the targets of histone-modifying enzymes seem to be relatively nonspecific; thus, manipulating these enzymes could influence more than one cell function. For instance, KDM4B and KDM6B regulate RUNX2 and SOX9 expression, which may facilitate both osteogenic and chondrogenic differentiation. Inhibition of G9a promotes adipogenic, endothelial, neuronal and cardiomyogenic differentiation. Similarly, EZH2 facilitates both adipogenic and neuronal differentiation and is also associated with cell senescence.

Therefore, precise, gene-specific control of certain histone-modifying enzymes remains a considerable challenge. However, there are a few possible directions for future research. First, a deeper and more systematic understanding of histone modification would help elucidate the gene-specific control of histone modification enzymes. In addition to more studies on individual histone modification marks or enzymes, comprehensive studies on the interactions of sequence-specific transcription factors with known histone modification systems are of great necessity and importance. Second, since some drugs or small molecules targeting histone-modifying enzymes have already been discovered and are even undergoing clinical trials [169-172], cocktails of several kinds of drugs should be investigated, as these might help enhance the specificity and efficiency of the existing compounds. Finally, coordination of the histone modification system with genome-editing techniques using CRISPR/ Cas9 [173] and other vectors [174] is a promising strategy for precise regulation.

In summary, histone modifications undoubtedly play important roles in the regulation of biological processes in MSCs. Precise control of these modifications in MSCs will not only help us understand their functions but also enable us to direct cell fate for optimal tissue regeneration and damage repair.

\section{Abbreviations}

ARDS: Acute respiratory distress syndrome; Arid5b: AT-rich interactive domain 5b; ASCOM: ASC-2 complex; BMSCs: Bone marrow stem cells; C/EBPa: CCAAT/ enhancer-binding protein alpha; CARM1: Coactivator-associated arginine methyltransferase 1; CMS: Cyclic mechanical stretch; COMP: Cartilage oligomeric matrix protein; CPPs: Cell-penetrating peptides; EHMT1: Euchromatin histone methyltransferase 1; ESCs: Embryonic stem cells; EZH2: Enhancer of zeste 2; GLP: G9a-like protein; GvHD: Graft-versus-host disease; H3K27: Histone H3 lysine 27; H3K36: Histone H3 lysine 36; H3K4: Histone H3 lysine 4; H3K9: Histone H3 lysine 9; H3R17: Hisotne H3 arginine 17; HAMSCs: Human amniotic mesenchymal stem cells; HAMSCs: Human amniotic MSCs; HATs: Histone acetyltransferases; HDACs: Histone deacetylases; HDMs: Histone demethylases; HMTs: Histone methyltransferases; hUC-MSCs: Human umbilical cord-derived mesenchymal stem cells; HUVECs: Human umbilical vein endothelial cells; IDH1: Isocitrate dehydrogenase 1; iPSC: Induced pluripotent stem cells; ISCT: International Society for Cellular Therapy; KDM2A: Lysine-specific demethylase 2A; KDM4B: Lysine-specific demethylase 4B; KDM5A: Lysine-specific demethylase 5A; KDM5B: Lysine-specific demethylase 5B; KDM6A: Lysine-specific demethylase 5A; KDM6B: Lysine-specific demethylase 5B; KO: Knockout; LRF: Leukemia/lymphoma-related factor; MLLs: Mixed lineage leukemias; MSCs: Mesenchymal stem cells; NaBu: Sodium butyrate; NRE: Negative regulatory element; OA: Osteoarthritis; OC: Osteocalcin; OFCD: Oculofaciocardiodental; OSX: Osterix; PBMCs: Peripheral blood mononuclear cells; PcG: Polycomb group; PPARy: Peroxisome proliferator-activated receptor gamma; PRMT: Protein arginine methyltransferase; RE-1: Repressor element-1; RUNX2: Runtrelated transcription factor 2; S1P: Sphingosine-1 phosphate; SAHA: Suberoylanilide hydroxamic acid; SCAPs: Stem cells from apical papilla; SFMCs: Synovial fluid mononuclear cells; TBI: Traumatic brain injury; TSA: Trichostatin A; TSSs: Transcription start sites; VPA: Valproic acid.

\section{Acknowledgements}

Not applicable.

\section{Authors' contributions}

JR completed the main part of the manuscript. DH and RL helped proofread the manuscript and make refinement. WW and CZ provided invaluable instructions during the process. All authors read and approved the final manuscript.

\section{Funding}

This work was supported by grants from National Key R\&D Program of China (2016YFC20160905200), National Natural Science Foundation of China (81600824), Natural Science Foundation of Guangdong Province (2016A030310220, 2018A030310278, 2015A030313880), Young Teachers Training Program of Sun Yat-sen University (16ykpy46, 17ykpy73), Science and Technology Program of Guangzhou (201707010106, 201804010459) and the Young Elite Scientist Sponsorship Program by CAST (2016QNRC001).

Availability of data and materials

Not applicable.

Ethics approval and consent to participate

Not applicable.

\section{Consent for publication}

Not applicable.

\section{Competing interests}

The authors declare that they have no competing interests.

Received: 18 May 2019 Accepted: 24 January 2020

Published online: 03 February 2020 


\section{References}

1. Ankrum JA, Ong JF, Karp JM. Mesenchymal stem cells: immune evasive, not immune privileged. Nat Biotechnol. 2014;32:252-60.

2. Friedenstein AJ, Petrakova KV, Kurolesova Al, Frolova GP. Heterotopic of bone marrow. Analysis of precursor cells for osteogenic and hematopoietic tissues. Transplantation. 1968;6:230-47.

3. Ozkul Y, Galderisi U. The impact of epigenetics on mesenchymal stem cell biology. J Cell Physiol. 2016;231:2393-401.

4. Dominici M, Le Blanc K, Mueller I, Slaper-Cortenbach I, Marini F, Krause D, Deans R, Keating A, Prockop D, Horwitz E. Minimal criteria for defining multipotent mesenchymal stromal cells. Int Soc Cell Ther Position Statement Cytother. 2006;8:315-7.

5. Nombela-Arrieta C, Ritz J, Silberstein LE. The elusive nature and function of mesenchymal stem cells. Nat Rev Mol Cell Biol. 2011;12:126-31.

6. Somoza R, Conget P, Rubio FJ. Neuropotency of human mesenchymal stem cell cultures: clonal studies reveal the contribution of cell plasticity and cell contamination. Biol Blood Marrow Transplant. 2008;14:546-55.

7. Ong S-Y, Dai H, Leong KW. Inducing hepatic differentiation of human mesenchymal stem cells in pellet culture. Biomaterials. 2006;27:4087-97.

8. Gao F, Wu D-Q, Hu Y-H, Jin G-X, Li G-D, Sun T-W, Li F-J. In vitro cultivation of islet-like cell clusters from human umbilical cord blood-derived mesenchymal stem cells. Transl Res. 2008;151:293-302.

9. Wang M, Yu Q, Wang L, Gu H. Distinct patterns of histone modifications at cardiac-specific gene promoters between cardiac stem cells and mesenchymal stem cells. Am J Physiol Cell Physiol. 2013;304:C1080-90.

10. Jeong SG, Ohn T, Kim SH, Cho GW. Valproic acid promotes neuronal differentiation by induction of neuroprogenitors in human bone-marrow mesenchymal stromal cells. Neurosci Lett. 2013;554:22-7.

11. Pittenger MF, Mackay AM, Beck SC, Jaiswal RK, Douglas R, Mosca JD, Moorman MA, Simonetti DW, Craig S, Marshak DR. Multilineage potential of adult human mesenchymal stem cells. Science. 1999;284:143-7.

12. Németh K, Leelahavanichkul A, Yuen PS, Mayer B, Parmelee A, Doi K, Robey PG, Leelahavanichkul K, Koller BH, Brown JM. Bone marrow stromal cells attenuate sepsis via prostaglandin E 2-dependent reprogramming of host macrophages to increase their interleukin-10 production. Nat Med. 2009;15:42.

13. Ward CL, Sanchez CJ Jr, Pollot BE, Romano DR, Hardy SK, Becerra SC, Rathbone CR, Wenke JC. Soluble factors from biofilms of wound pathogens modulate human bone marrow-derived stromal cell differentiation, migration, angiogenesis, and cytokine secretion. BMC Microbiol. 2015:15:75.

14. Yuan Y, Guo N, Zhao C, Shen S, Bu X, Ye H. Marrow mesenchymal stromal cells reduce methicillin-resistant Staphylococcus aureus infection in rat models. Cytotherapy. 2014;16:56-63.

15. Walter J, Ware LB, Matthay MA. Mesenchymal stem cells: mechanisms of potential therapeutic benefit in ARDS and sepsis. Lancet Respir Med. 2014;2:1016-26.

16. Oh K-W, Moon C, Kim HY, Oh S-I, Park J, Lee JH, Chang IY, Kim KS, Kim $\mathrm{SH}$. Phase I trial of repeated intrathecal autologous bone marrowderived mesenchymal stromal cells in amyotrophic lateral sclerosis. Stem Cells Transl Med. 2015;4:590-7.

17. Zhao Q, Ren H, Han Z. Mesenchymal stem cells: immunomodulatory capability and clinical potential in immune diseases. J Cell Immunother. 2016:2:3-20.

18. Gao F, Chiu S, Motan D, Zhang Z, Chen L, Ji H, Tse H, Fu Q-L, Lian Q. Mesenchymal stem cells and immunomodulation: current status and future prospects. Cell Death Dis. 2016;7:e2062.

19. Han YS, Kim SM, Lee JH, Jung SK, Noh H, Lee SH. Melatonin protects chronic kidney disease mesenchymal stem cells against senescence via PrPC-dependent enhancement of the mitochondrial function. J Pineal Res. 2019;66:e12535.

20. Muroi K, Miyamura K, Okada M, Yamashita T, Murata M, Ishikawa T, Uike N, Hidaka M, Kobayashi R, Imamura M. Bone marrow-derived mesenchymal stem cells (JR-031) for steroid-refractory grade III or IV acute graft-versus-host disease: a phase II/III study. Int J Hematol. 2016;103:243-50

21. Swygert SG, Peterson CL. Chromatin dynamics: interplay between remodeling enzymes and histone modifications. Biochimica et Biophysica Acta (BBA) Gene Regul Mech. 2014;1839:728-36.
22. Bannister AJ, Kouzarides T. Regulation of chromatin by histone modifications. Cell Res. 2011;21:381-95.

23. Li X, Harris CJ, Zhong Z, Chen W, Liu R, Jia B, Wang Z, Li S, Jacobsen SE, Du J. Mechanistic insights into plant SUVH family H3K9 methyltransferases and their binding to context-biased non-CG DNA methylation. Proc Natl Acad Sci. 2018;115:E8793-802.

24. Zhang Z, Nikolai BC, Gates LA, Jung SY, Siwak EB, He B, Rice AP, O'Malley BW, Feng Q. Crosstalk between histone modifications indicates that inhibition of arginine methyltransferase CARM1 activity reverses HIV latency. Nucleic Acids Res. 2017;45:9348-60.

25. Ramakrishnan S, Pokhrel S, Palani S, Pflueger C, Parnell TJ, Cairns BR, Bhaskara S, Chandrasekharan MB. Counteracting H3K4 methylation modulators Set 1 and Jhd2 co-regulate chromatin dynamics and gene transcription. Nat Commun. 2016;7:11949.

26. Ortega E, Rengachari S, Ibrahim Z, Hoghoughi N, Gaucher J, Holehouse AS, Khochbin S, Panne D. Transcription factor dimerization activates the p300 acetyltransferase. Nature. 2018;562:538.

27. Puttagunta R, Tedeschi A, Sória MG, Hervera A, Lindner R, Rathore KI, Gaub P, Joshi Y, Nguyen T, Schmandke A. PCAF-dependent epigenetic changes promote axonal regeneration in the central nervous system. Nat Commun. 2014;5:3527.

28. Biswas S, Rao CM. Epigenetic tools (The Writers, The Readers and The Erasers) and their implications in cancer therapy. Eur J Pharmacol. 2018:837:8-24.

29. de Semir D, Bezrookove V, Nosrati M, Dar AA, Wu C, Shen J, Rieken C, Venkatasubramanian M, Miller JR, Desprez P-Y. PHIP as a therapeutic target for driver-negative subtypes of melanoma, breast, and lung cancer. Proc Natl Acad Sci. 2018;115:E5766-75.

30. Lin GL, Hankenson KD. Integration of BMP, Wnt, and notch signaling pathways in osteoblast differentiationt. J Cell Biochem. 2011:112:3491-501.

31. Crane $J$, Cao X. Bone marrow mesenchymal stem cells and TGF- $\beta$ signaling in bone remodeling. J Clin Investig. 2014;124:466-72.

32. Xu C, Wang J, Zhu T, Shen Y, Tang X, Fang L, Xu Y. Cross-talking between PPAR and WNT signaling and its regulation in mesenchymal stem cell differentiation. Curr Stem Cell Res Ther. 2016;11:247-54

33. Augello A, De Bari C. The regulation of differentiation in mesenchymal stem cells. Human Gene Ther. 2010;21:1226-38.

34. Mortada I, Mortada R. Epigenetic changes in mesenchymal stem cells differentiation. Eur J Med Genet. 2017;61:114-8.

35. Huang $B$, Li G, Jiang XH. Fate determination in mesenchymal stem cells: a perspective from histone-modifying enzymes. Stem Cell Res Ther. 2015;6:35.

36. Meyer MB, Benkusky NA, Sen B, Rubin J, Pike JW. Epigenetic plasticity drives adipogenic and osteogenic differentiation of marrow-derived mesenchymal stem cells. J Biol Chem. 2016;291:17829-47.

37. Musri MM, Gomis R, Párrizas M. A chromatin perspective of adipogenesis. Organogenesis. 2010;6:15-23.

38. Long MW, Robinson J, Ashcraft E, Mann KG. Regulation of human bone marrow-derived osteoprogenitor cells by osteogenic growth factors. J Clin Investig. 1995:95:881-7.

39. Chen Q, Shou P, Zheng C, Jiang M, Cao G, Yang Q, Cao J, Xie N, Velletri $T$, Zhang $X$. Fate decision of mesenchymal stem cells: adipocytes or osteoblasts|[quest]. Cell Death Differ. 2016;23:1128-39.

40. Fan Z, Yamaza T, Lee JS, Yu J, Wang S, Fan G, Shi S, Wang CY. BCOR regulates mesenchymal stem cell function by epigenetic mechanisms. Nat Cell Biol. 2009;11:1002-9.

41. Ganguly P, Eljawhari JJ, Giannoudis PV, Burska AN, Ponchel F, Jones EA. Age-related changes in bone marrow mesenchymal stromal cells: a potential impact on osteoporosis and osteoarthritis development. Cell Transpl. 2017;26:1520-9.

42. Tan J, Lu J, Huang W, Dong Z, Kong C, Li L, Gao L, Guo J, Huang B. Genome-wide analysis of histone $\mathrm{H} 3$ lysine9 modifications in human mesenchymal stem cell osteogenic differentiation. PLOS ONE. 2009;4:e6792.

43. Rodríguez JP, Astudillo P, Rios S, Pino AM. Involvement of adipogenic potential of human bone marrow mesenchymal stem cells (MSCs) in osteoporosis. Curr Stem Cell Res Ther. 2008;3:208-18.

44. Zuscik MJ, Hilton MJ, Zhang X, Chen D, O'Keefe RJ. Regulation of chondrogenesis and chondrocyte differentiation by stress. J Clin Investig. 2008;118:429-38 
45. Herlofsen SR, Bryne JC, Høiby T, Wang L, Issner R, Zhang X, Coyne MJ, Boyle P, Gu H, Meza-Zepeda LA. Genome-wide map of quantified epigenetic changes during in vitro chondrogenic differentiation of primary human mesenchymal stem cells. BMC Genom. 2013;14:1-18.

46. Herlofsen SR, Bryne JC, Hoiby T, Wang L, Issner R, Zhang X, Coyne MJ, Boyle P, Gu H, Meza-Zepeda LA, Collas P, Mikkelsen TS, Brinchmann JE. Genome-wide map of quantified epigenetic changes during in vitro chondrogenic differentiation of primary human mesenchymal stem cells. BMC Genom. 2013;14:105.

47. Dhar SS, Zhao D, Lin T, Gu B, Pal K, Wu SJ, Alam H, Lv J, Yun K, Gopalakrishnan V. MLL4 is required to maintain broad H3K4me3 peaks and super-enhancers at tumor suppressor genes. Mol Cell. 2018:70:825-41.

48. Cruz C, Della Rosa M, Krueger C, Gao Q, Horkai D, King M, Field L, Houseley J. Tri-methylation of histone $\mathrm{H} 3$ lysine 4 facilitates gene expression in ageing cells. eLife. 2018;7:e34081.

49. Guenther MG, Levine SS, Boyer LA, Jaenisch R, Young RA. A chromatin landmark and transcription initiation at most promoters in human cells. Cell. 2007;130:77-88.

50. Hassan MQ, Tare R, Lee SH, Mandeville M, Weiner B, Montecino M, van Wijnen AJ, Stein JL, Stein GS, Lian JB. HOXA10 controls osteoblastogenesis by directly activating bone regulatory and phenotypic genes. Mol Cell Biol. 2007;27:3337-52

51. Busto F, Sepúlveda H, Prieto CP, Carrasco M, Díaz L, Palma J, Lattus J, Montecino M, Palma V. Runt-related transcription factor 2 induction during differentiation of Wharton's Jelly mesenchymal stem cells to osteoblasts is regulated by Jumonji AT-rich interactive domain 1B histone demethylase. Stem Cells. 2017;35:2430-41.

52. Wang C, Wang J, Li J, Hu G, Shan S, Li Q, Zhang X. KDM5A controls bone morphogenic protein 2-induced osteogenic differentiation of bone mesenchymal stem cells during osteoporosis. Cell Death Dis. 2016;7:e2335

53. Tucker A, Sharpe P. The cutting-edge of mammalian development; how the embryo makes teeth. Nat Rev Genet. 2004;5:499-508.

54. Cai X, Gong P, Huang Y, Lin Y. Notch signalling pathway in tooth development and adult dental cells. Cell Prolif. 2011;44:495-507.

55. O'Connell DJ, Ho JW, Mammoto T, Turbe-Doan A, O'Connell JT, Haseley PS, Koo S, Kamiya N, Ingber DE, Park PJ. A Wnt-bmp feedback circuit controls intertissue signaling dynamics in tooth organogenesis. Sci Signal. 2012;5:ra4.

56. Zhou Y, Zheng L, Li F, Wan M, Fan Y, Zhou X, Du W, Pi C, Cui D, Zhang B. Bivalent histone codes on WNT5A during odontogenic differentiation. J Dent Res. 2018;97:99-107.

57. Musri MM, Corominola H, Casamitjana R, Gomis R, Párrizas M. Histone $\mathrm{H} 3$ lysine 4 dimethylation signals the transcriptional competence of the adiponectin promoter in preadipocytes. J Biol Chem. 2006;281:17180-8.

58. Lee J, Saha PK, Yang QH, Lee S, Park JY, Suh Y, Lee SK, Chan L, Roeder RG, Lee JW. Targeted inactivation of MLL3 histone H3-Lys-4 methyltransferase activity in the mouse reveals vital roles for MLL3 in adipogenesis. Proc Natl Acad Sci USA. 2008;105:19229-34.

59. Yin B, Yu F, Wang C, Li B, Liu M, Ye L. Epigenetic control of mesenchymal stem cell fate decision via histone methyltransferase Ash1l. Stem Cells. 2019;37:115-27.

60. Dong R, Yao R, Du J, Wang S, Fan Z. Depletion of histone demethylase KDM2A enhanced the adipogenic and chondrogenic differentiation potentials of stem cells from apical papilla. Exp Cell Res. 2013;319:2874-82.

61. Audergon PN, Catania S, Kagansky A, Tong P, Shukla M, Pidoux AL, Allshire RC. Restricted epigenetic inheritance of H3K9 methylation. Science. 2015;348:132-5.

62. Liu N, Zhang Z, Wu H, Jiang Y, Meng L, Xiong J, Zhao Z, Zhou X, Li J, $\mathrm{Li} \mathrm{H}$. Recognition of H3K9 methylation by GLP is required for efficient establishment of H3K9 methylation, rapid target gene repression, and mouse viability. Genes Dev. 2015;29:379-93.

63. Lawson KA, Teteak CJ, Gao J, Li N, Hacquebord J, Ghatan A, ZielinskaKwiatkowska A, Song G, Chansky HA, Yang L. ESET histone methyltransferase regulates osteoblastic differentiation of mesenchymal stem cells during postnatal bone development. FEBS Lett. 2013;587:3961-7.

64. Balemans MC, Ansar M, Oudakker AR, van Caam AP, Bakker B, Vitters EL, van der Kraan PM, de Bruijn DR, Janssen SM, Kuipers AJ. Reduced Euchromatin histone methyltransferase 1 causes developmental delay, hypotonia, and cranial abnormalities associated with increased bone gene expression in Kleefstra syndrome mice. Dev Biol. 2014:386:395-407.

65. Ye L, Fan Z, Yu B, Chang J, Al Hezaimi K, Zhou X, Park NH, Wang CY. Histone demethylases KDM4B and KDM6B promotes osteogenic differentiation of human MSCs. Cell Stem Cell. 2012;11:50-61.

66. Wang L, Xu S, Baldridge A, Grullon S, Peng W, Ge K. Histone H3K9 methyltransferase G9a represses PPARy expression and adipogenesis. EMBO J. 2013:32:45-59.

67. Lee KH, Ju UI, Song JY, Chun YS. The histone demethylase PHF2 promotes fat cell differentiation as an epigenetic activator of both C/ EBPalpha and C/EBPdelta. Mol Cells. 2014;37:734-41.

68. Lu C, Ward PS, Kapoor GS, Rohle D, Turcan S, Abdel-Wahab O, Edwards CR, Khanin R, Figueroa ME, Melnick A, Wellen KE, O'Rourke DM, Berger SL, Chan TA, Levine RL, Mellinghoff IK, Thompson CB. IDH mutation impairs histone demethylation and results in a block to cell differentiation. Nature. 2012;483:474-8.

69. Buerger F, Muller S, Ney N, Weiner J, Heiker JT, Kallendrusch S, Kovacs P, Schleinitz D, Thiery J, Stadler SC, Burkhardt R. Depletion of Jmjd1C impairs adipogenesis in murine 3T3-L1 cells. Biochim Biophys Acta Mol Basis Dis. 1863;2017:1709-17.

70. Musri MM, Carmona MC, Hanzu FA, Kaliman P, Gomis R, Parrizas M. Histone demethylase LSD1 regulates adipogenesis. J Biol Chem. 2010:285:30034-41.

71. Matsumura Y, Nakaki R, Inagaki T, Yoshida A, Kano Y, Kimura H, Tanaka T, Tsutsumi S, Nakao M, Doi T. H3K4/H3K9me3 bivalent chromatin domains targeted by lineage-specific DNA methylation pauses adipocyte differentiation. Mol Cell. 2015;60:584-96.

72. Chen Y, Kim J, Zhang R, Yang X, Zhang Y, Fang J, Chen Z, Teng L, Chen X, Ge H, Atadja P, Li E, Chen T, Qi W. Histone demethylase LSD1 promotes adipocyte differentiation through repressing Wnt signaling. Cell Chem Biol. 2016;23:1228-40

73. Lee HL, Yu B, Deng P, Wang CY, Hong C. Transforming growth factor$\beta$-induced KDM4B promotes chondrogenic differentiation of human mesenchymal stem cells. Stem Cells. 2016:34:711-9.

74. Yamada T, Nabe S, Toriyama K, Suzuki J, Inoue K, Imai Y, Shiraishi A, Takenaka K, Yasukawa M, Yamashita M. Histone H3K27 demethylase negatively controls the memory formation of antigen-stimulated CD8+ T cells. J Immunol. 2019;202:1088-98.

75. Chen H, Huang Y, Zhu X, Liu C, Yuan Y, Su H, Zhang C, Liu C, Xiong M, Qu Y. Histone demethylase UTX is a therapeutic target for diabetic kidney disease. J Physiol. 2019;597:1643-60.

76. Chen S, Pu J, Bai J, Yin Y, Wu K, Wang J, Shuai X, Gao J, Tao K, Wang G. EZH2 promotes hepatocellular carcinoma progression through modulating miR-22/galectin-9 axis. J Exp Clin Cancer Res. 2018;37:3.

77. Wu H, Gordon JA, Whitfield TW, Tai PW, van Wijnen AJ, Stein JL, Stein GS, Lian JB. Chromatin dynamics regulate mesenchymal stem cell lineage specification and differentiation to osteogenesis. Biochimica et Biophysica Acta (BBA) Gene Regul Mech. 2017;1860:438-49.

78. Di Croce L, Helin K. Transcriptional regulation by Polycomb group proteins. Nat Struct Mol Biol. 2013;20:1147.

79. Wang L, Jin Q, Lee J-E, Su I-H, Ge K. Histone H3K27 methyltransferase Ezh2 represses Wnt genes to facilitate adipogenesis. Proc Natl Acad Sci. 2010;107:7317-22.

80. Wei Y, Chen YH, Li LY, Lang J, Yeh SP, Shi B, Yang CC, Yang JY, Lin CY, Lai CC, Hung MC. CDK1-dependent phosphorylation of EZH2 suppresses methylation of $\mathrm{H} 3 \mathrm{~K} 27$ and promotes osteogenic differentiation of human mesenchymal stem cells. Nat Cell Biol. 2011;13:87-94.

81. Hemming S, Cakouros D, Isenmann S, Cooper L, Menicanin D, Zannettino A, Gronthos S. EZH2 and KDM6A act as an epigenetic switch to regulate mesenchymal stem cell lineage specification. Stem Cells. 2014;32:802-15.

82. Hemming S, Cakouros D, Vandyke K, Davis MJ, Zannettino AC, Gronthos S. Identification of novel EZH2 targets regulating osteogenic differentiation in mesenchymal stem cells. Stem Cells Dev. 2016:25:909-21.

83. Yi SA, Um SH, Lee J, Yoo JH, Bang SY, Park EK, Lee MG, Nam KH, Jeon YJ, Park JW. S6K1 phosphorylation of H2B mediates EZH2 trimethylation of $\mathrm{H} 3$ : a determinant of early adipogenesis. Mol Cell. 2016;62:443-52. 
84. Yapp C, Carr AJ, Price A, Oppermann U, Snelling SJB. H3K27me3 demethylases regulate in vitro chondrogenesis and chondrocyte activity in osteoarthritis. Arthr Res Ther. 2016;18:S181-S181.

85. Zhang F, Xu L, Xu L, Xu Q, Li D, Yang Y, Karsenty G, Chen CD. Editor's choice: JMJD3 promotes chondrocyte proliferation and hypertrophy during endochondral bone formation in mice. J Mol Cell Biol. 2015;7:23-34

86. Wang P, Li Y, Meng T, Zhang J, Wei Y, Meng Z, Lin Y, Liu D, Sui L. KDM6A promotes chondrogenic differentiation of periodontal ligament stem cells by demethylation of SOX9. Cell Prolif. 2017;51:e12413.

87. Dai J, Yu D, Wang Y, Chen Y, Sun H, Zhang X, Zhu S, Pan Z, Heng BC, Zhang S. Kdm6b regulates cartilage development and homeostasis through anabolic metabolism. Ann Rheum Dis. 2017;76:1295.

88. Wang L, Niu N, Li L, Shao R, Ouyang H, Zou W. H3K36 trimethylation mediated by SETD2 regulates the fate of bone marrow mesenchymal stem cells. PLoS Biol. 2018;16:e2006522.

89. Lu C, Jain SU, Hoelper D, Bechet D, Molden RC, Ran L, Murphy D, Venneti S, Hameed M, Pawel BR. Histone H3K36 mutations promote sarcomagenesis through altered histone methylation landscape. Science. 2016;352:844-9.

90. Zhuang L, Jang Y, Park Y-K, Lee J-E, Jain S, Froimchuk E, Broun A, Liu C, Gavrilova O, Ge K. Depletion of Nsd2-mediated histone H3K36 methylation impairs adipose tissue development and function. Nat Commun. 2018:9:1796.

91. Talasz H, Lindner HH, Sarg B, Helliger W. Histone H4-lysine 20 monomethylation is increased in promoter and coding regions of active genes and correlates with hyperacetylation. J Biol Chem. 2005;280:38814-22.

92. Evertts AG, Manning AL, Wang X, Dyson NJ, Garcia BA, Coller HA. H4K20 methylation regulates quiescence and chromatin compaction. Mol Biol Cell. 2013;24:3025-37

93. Yang H, Kwon CS, Choi Y, Lee D. Both H4K20 mono-methylation and H3K56 acetylation mark transcription-dependent histone turnover in fission yeast. Biochem Biophys Res Commun. 2016;476:515-21.

94. Wakabayashi K, Okamura M, Tsutsumi S, Nishikawa NS, Tanaka T, Sakakibara I, Kitakami J, Ihara S, Hashimoto Y, Hamakubo T, Kodama T, Aburatani H, Sakai J. The peroxisome proliferator-activated receptor gamma/retinoid $X$ receptor alpha heterodimer targets the histone modification enzyme PR-Set7/Setd8 gene and regulates adipogenesis through a positive feedback loop. Mol Cell Biol. 2009;29:3544-55.

95. Jo J, Song H, Park SG, Lee SH, Ko JJ, Park JH, Jeong J, Cheon YP, Lee DR. Regulation of differentiation potential of human mesenchymal stem cells by intracytoplasmic delivery of coactivator-associated arginine methyltransferase 1 protein using cell-penetrating peptide. Stem Cells. 2012;30:1703-13.

96. Casadio F, Lu X, Pollock SB, LeRoy G, Garcia BA, Muir TW, Roeder RG, Allis CD. H3R42me2a is a histone modification with positive transcriptional effects. Proc Natl Acad Sci. 2013;110:14894-9.

97. Yadav N, Cheng D, Richard S, Morel M, lyer VR, Aldaz CM, Bedford MT. CARM1 promotes adipocyte differentiation by coactivating PPARY. EMBO Rep. 2008;9:193-8.

98. LeBlanc SE, Konda S, Wu Q, Hu Y-J, Oslowski CM, Sif S, Imbalzano AN. Protein arginine methyltransferase 5 (Prmt5) promotes gene expression of peroxisome proliferator-activated receptor $\gamma 2$ (PPARY2) and its target genes during adipogenesis. Mol Endocrinol. 2012;26:583-97.

99. Jing H, Su X, Gao B, Shuai Y, Chen J, Deng Z, Liao L, Jin Y. Epigenetic inhibition of Wnt pathway suppresses osteogenic differentiation of BMSCs during osteoporosis. Cell Death Dis. 2018;9:176.

100. Hartig SM, He B, Long W, Buehrer BM, Mancini MA. Homeostatic levels of SRC-2 and SRC-3 promote early human adipogenesis. J Cell Biol. 2011;192:55-67.

101. Wiper-Bergeron N, Salem HA, Tomlinson JJ, Wu D, Haché RJ. Glucocorticoid-stimulated preadipocyte differentiation is mediated through acetylation of C/EBPß by GCN5. Proc Natl Acad Sci. 2007;104:2703-8.

102. Gelman L, Zhou G, Fajas L, Raspé E, Fruchart J-C, Auwerx J. p300 interacts with the $\mathrm{N}$-and $\mathrm{C}$-terminal part of PPARY2 in a ligand-independent and-dependent manner, respectively. J Biol Chem. 1999:274:7681-8.

103. Zhang P, Liu Y, Jin C, Zhang M, Tang F, Zhou Y. Histone acetyltransferase GCN5 regulates osteogenic differentiation of mesenchymal stem cells by inhibiting NF-kB. J Bone Miner Res. 2016;31:391-402.
104. Dudakovic A, Evans JM, LiY, Middha S, McGee-Lawrence ME, Van Wijnen AJ, Westendorf JJ. Histone deacetylase inhibition promotes osteoblast maturation by altering the histone $\mathrm{H} 4$ epigenome and reduces Akt phosphorylation. J Biol Chem. 2013;288:28783-91.

105. Maroni P, Brini AT, Arrigoni E, de Girolamo L, Niada S, Matteucci E, Bendinelli P, Desiderio MA. Chemical and genetic blockade of HDACs enhances osteogenic differentiation of human adipose tissue-derived stem cells by oppositely affecting osteogenic and adipogenic transcription factors. Biochem Biophys Res Commun. 2012:428:271-7.

106. Huynh NCN, Everts V, Pavasant P. Inhibition of histone deacetylases enhances the osteogenic differentiation of human periodontal ligament cells. J Cell Biochem. 2016;117:1384-95.

107. Westendorf JJ, Zaidi SK, Cascino JE, Kahler R, Van Wijnen AJ, Lian JB, Yoshida M, Stein GS, Li X. Runx2 (Cbfa1, AML-3) interacts with histone deacetylase 6 and represses the p21CIP1/WAF1 promoter. Mol Cell Biol. 2002;22:7982-92.

108. Huang S, Wang S, Bian C, Yang Z, Zhou H, Zeng Y, Li H, Han Q, Zhao $\mathrm{RC}$. Upregulation of miR-22 promotes osteogenic differentiation and inhibits adipogenic differentiation of human adipose tissue-derived mesenchymal stem cells by repressing HDAC6 protein expression. Stem Cells Dev. 2012;21:2531-40.

109. Rimando MG, Wu H-H, Liu Y-A, Lee C-W, Kuo S-W, Lo Y-P, Tseng K-F, Liu Y-S, Lee OK-S. Glucocorticoid receptor and Histone deacetylase 6 mediate the differential effect of dexamethasone during osteogenesis of mesenchymal stromal cells (MSCs). Sci Rep. 2016;6:37371.

110. Lee HW, Suh JH, Kim AY, Lee YS, Park SY, Kim JB. Histone deacetylase 1-mediated histone modification regulates osteoblast differentiation. Mol Endocrinol. 2006;20:2432-43.

111. Hao J, Zhang Y, Jing D, Shen Y, Tang G, Huang S, Zhao Z. Mechanobiology of mesenchymal stem cells: perspective into mechanical induction of MSC fate. Acta Biomater. 2015:20:1-9.

112. Wang J, Wang CD, Zhang N, Tong WX, Zhang YF, Shan SZ, Zhang XL, Li QF. Mechanical stimulation orchestrates the osteogenic differentiation of human bone marrow stromal cells by regulating HDAC1. Cell Death Dis. 2016:7:e2221

113. Feigenson M, Shull LC, Taylor EL, Camilleri ET, Riester SM, van Wijnen AJ, Bradley EW, Westendorf JJ. Histone deacetylase 3 deletion in mesenchymal progenitor cells hinders long bone development. J Bone Miner Res. 2017;32:2453-65

114. Xiao T, Fu Y, Zhu W, Xu R, Xu L, Zhang P, Du Y, Cheng J, Jiang H. HDAC8, a potential therapeutic target, regulates proliferation and differentiation of bone marrow stromal cells in fibrous dysplasia. Stem Cells Transl Med. 2018;8:148-61.

115. Takahashi N, Kawada T, Yamamoto T, Goto T, Taimatsu A, Aoki N, Kawasaki H, Taira K, Yokoyama KK, Kamei Y. Overexpression and ribozymemediated targeting of transcriptional coactivators CREB-binding protein and p300 revealed their indispensable roles in adipocyte differentiation through the regulation of peroxisome proliferator-activated receptor gamma. J Biol Chem. 2002;277:16906-12.

116. Badri KR, Zhou Y, Dhru U, Aramgam S, Schuger L. Effects of the SANT domain of tension-induced/inhibited proteins (TIPs), novel partners of the histone acetyltransferase p300, on p300 activity and TIP-6-induced adipogenesis. Mol Cell Biol. 2008;28:6358-72.

117. Ramlee MK, Zhang Q, Idris M, Peng X, Sim CK, Han W, Xu F. Histone H3 K27 acetylation marks a potent enhancer element on the adipogenic master regulator gene Pparg2. Cell Cycle (Georgetown, Tex.). 2014;13:3414-22

118. Jin Q, Wang C, Kuang X, Feng X, Sartorelli V, Ying H, Ge K, Dent SY. Gcn5 and PCAF regulate PPARgamma and Prdm16 expression to facilitate brown adipogenesis. Mol Cell Biol. 2014;34:3746-53.

119. Yoo EJ, Chung JJ, Choe SS, Kim KH, Kim JB. Down-regulation of histone deacetylases stimulates adipocyte differentiation. J Biol Chem. 2006;281:6608-15.

120. Chatterjee TK, Idelman G, Blanco V, Blomkalns AL, Piegore M, Weintraub DS, Kumar S, Rajsheker S, Manka D, Rudich SM. Histone deacetylase 9 is a negative regulator of adipogenic differentiation. J Biol Chem. 2011;286:27836-47

121. Tsuda M, Takahashi S, Takahashi Y, Asahara H. Transcriptional coactivators CREB-binding protein and $\mathrm{p300}$ regulate chondrocytespecific gene expression via association with Sox9. J Biol Chem. 2003:278:27224-9. 
122. Furumatsu T, Tsuda M, Yoshida K, Taniguchi N, Ito T, Hashimoto M, Ito T, Asahara H. Sox9 and p300 cooperatively regulate chromatin-mediated transcription. J Biol Chem. 2005;280:35203-8.

123. Liu C, Prazak L, Fajardo M, Yu S, Tyagi N, Cesare PED. Leukemia/ lymphoma-related factor, a POZ domain-containing transcriptional repressor, interacts with histone deacetylase-1 and inhibits cartilage oligomeric matrix protein gene expression and chondrogenesis. J Biol Chem. 2004;279:47081-91.

124. Huang X, Xu J, Huang M, Li J, Dai L, Dai K, Zhang X. Histone deacetylase 1 promotes TGF- $\beta 1$-mediated early chondrogenesis through downregulating canonical Wnt signaling. Biochem Biophys Res Commun. 2014:453:810-6.

125. Vega RB, Matsuda K, Oh J, Barbosa AC, Yang X, Meadows E, McAnally J, Pomajzl C, Shelton JM, Richardson JA, Karsenty G, Olson EN. Histone deacetylase 4 controls chondrocyte hypertrophy during skeletogenesis. Cell. 2004;119:555-66.

126. Bradley EW, Carpio LR, Olson EN, Westendorf JJ. Histone deacetylase 7 (Hdac7) suppresses chondrocyte proliferation and beta-catenin activity during endochondral ossification. J Biol Chem. 2015;290:118-26.

127. Bradley EW, Carpio LR, Westendorf JJ. Histone deacetylase 3 suppression increases $\mathrm{PH}$ domain and leucine-rich repeat phosphatase (Ph/pp) 1 expression in chondrocytes to suppress Akt signaling and matrix secretion. J Biol Chem. 2013;288:9572-82.

128. Yu YL, Chou RH, Chen LT, Shyu WC, Hsieh SC, Wu CS, Zeng HJ, Yeh SP, Yang DM, Hung SC, Hung MC. EZH2 regulates neuronal differentiation of mesenchymal stem cells through PIP5K1C-dependent calcium signaling. J Biol Chem. 2011;286:9657-67.

129. Kim H-T, Jeong S-G, Cho G-W. G9a inhibition promotes neuronal differentiation of human bone marrow mesenchymal stem cells through the transcriptional induction of RE-1 containing neuronal specific genes. Neurochem Int. 2016;96:77-83.

130. Talwadekar M, Fernandes S, Kale V, Limaye L. Valproic acid enhances the neural differentiation of human placenta derived-mesenchymal stem cells in vitro. J Tissue Eng Regener Med. 2017;11:3111-23.

131. Jang $\mathrm{S}$, Jeong H-S. Histone deacetylase inhibition-mediated neuronal differentiation via the Wnt signaling pathway in human adipose tissuederived mesenchymal stem cells. Neurosci Lett. 2018;668:24-30.

132. Feng C, Zhu J, Zhao L, Lu T, Zhang W, Liu Z, Tian J. Suberoylanilide hydroxamic acid promotes cardiomyocyte differentiation of rat mesenchymal stem cells. Exp Cell Res. 2009;315:3044-51.

133. Li L, Zhu J, Tian J, Liu X, Feng C. A role for Gen5 in cardiomyocyte differentiation of rat mesenchymal stem cells. Mol Cell Biochem. 2010;345:309-16.

134. Yi Q, Xu H, Yang K, Wang Y, Tan B, Tian J, Zhu J. Islet-1 induces the differentiation of mesenchymal stem cells into cardiomyocyte-like cells through the regulation of Gcn5 and DNMT-1. Mol Med Rep. 2017;15:2511-20

135. Lu D-F, Wang Y, Su Z-Z, Zeng Z-H, Xing X-W, He Z-Y, Zhang C. Knockdown of the HDAC1 promotes the directed differentiation of bone mesenchymal stem cells into cardiomyocytes. PLOS ONE. 2014:9:e92179.

136. Snykers S, Vanhaecke T, De Becker A, Papeleu P, Vinken M, Van Riet I, Rogiers V. Chromatin remodeling agent trichostatin A: a key-factor in the hepatic differentiation of human mesenchymal stem cells derived of adult bone marrow. BMC Dev Biol. 2007;7:24

137. Cipriano M, Correia J, Camoes S, Oliveira N, Cruz P, Cruz H, Castro M, Ruas J, Santos J, Miranda J. The role of epigenetic modifiers in extended cultures of functional hepatocyte-like cells derived from human neonatal mesenchymal stem cells. Arch Toxicol. 2017;91:2469-89.

138. Dong X, Pan R, Zhang H, Yang C, Shao J, Xiang L. Modification of histone acetylation facilitates hepatic differentiation of human bone marrow mesenchymal stem cells. PLoS ONE. 2013;8:e63405.

139. Culmes M, Eckstein HH, Burgkart R, Nussler AK, Guenther M, Wagner E, Pelisek J. Endothelial differentiation of adipose-derived mesenchymal stem cells is improved by epigenetic modifying drug BIX-01294. Eur J Cell Biol. 2013;92:70-9.

140. DiGirolamo CM, Stokes D, Colter D, Phinney DG, Class R, Prockop DJ. Propagation and senescence of human marrow stromal cells in culture: a simple colony-forming assay identifies samples with the greatest potential to propagate and differentiate. Br J Haematol. 1999:107:275-81.
141. Wagner W, Bork S, Lepperdinger G, Joussen S, Ma N, Strunk D, Koch C. How to track cellular aging of mesenchymal stromal cells? Aging (Albany NY). 2010;2:224

142. Li Y, Wu Q, Wang Y, Li L, Bu H, Bao J. Senescence of mesenchymal stem cells. Int J Mol Med. 2017;39:775-82.

143. Wang Y, Yuan Q, Xie L. Histone modifications in aging: the underlying mechanisms and implications. Curr Stem Cell Res Ther. 2018;13:125-35.

144. Fernández AF, Bayón GF, Urdinguio RG, Toraño EG, García MG, Carella A, Petrus-Reurer S, Ferrero C, Martinez-Camblor P, Cubillo I. H3K4me1 marks DNA regions hypomethylated during aging in human stem and differentiated cells. Genome Res. 2015;25:27-40.

145. Molofsky AV, Pardal R, Iwashita T, Park IK, Clarke MF, Morrison SJ. Bmi-1 dependence distinguishes neural stem cell self-renewal from progenitor proliferation. Nature. 2003;425:962.

146. Iwama A, Oguro H, Negishi M, Kato Y, Morita Y, Tsukui H, Ema H, Kamijo T, Katoh-Fukui Y, Koseki H. Enhanced self-renewal of hematopoietic stem cells mediated by the polycomb gene product Bmi-1. Immunity. 2004:21:843-51.

147. Li C, Chai Y, Wang L, Gao B, Chen H, Gao P, Zhou F-Q, Luo X, Crane JL, Yu B. Programmed cell senescence in skeleton during late puberty. Nat Commun. 2017:8:1312.

148. Zhang W, Li J, Suzuki K, Qu J, Wang P, Zhou J, Liu X, Ren R, Xu X, Ocampo A. A Werner syndrome stem cell model unveils heterochromatin alterations as a driver of human aging. Science. 2015;348:1160-3.

149. Li Z, Liu C, Xie Z, Song P, Zhao RC, Guo L, Liu Z, Wu Y. Epigenetic dysregulation in mesenchymal stem cell aging and spontaneous differentiation. PLoS ONE. 2011;6:e20526.

150. Kim M, Kim C, Choi YS, Kim M, Park C, Suh Y. Age-related alterations in mesenchymal stem cells related to shift in differentiation from osteogenic to adipogenic potential: implication to age-associated bone diseases and defects. Mech Ageing Dev. 2012;133:215-25.

151. Bonab MM, Alimoghaddam K, Talebian F, Ghaffari SH, Ghavamzadeh A, Nikbin B. Aging of mesenchymal stem cell in vitro. BMC Cell Biol. 2006;7:14.

152. Bethel M, Chitteti BR, Srour EF, Kacena MA. The changing balance between osteoblastogenesis and adipogenesis in aging and its impact on hematopoiesis. Curr Osteoporos Rep. 2013;11:99-106.

153. Noer A, Lindeman LC, Collas P. Histone H3 modifications associated with differentiation and long-term culture of mesenchymal adipose stem cells. Stem Cells Dev. 2009;18:725-36.

154. Jung J-W, Lee S, Seo M-S, Park S-B, Kurtz A, Kang S-K, Kang K-S. Histone deacetylase controls adult stem cell aging by balancing the expression of polycomb genes and jumonji domain containing 3. Cell Mol Life Sci. 2010;67:1165-76.

155. Zhu Y, Song X, Han F, Li Y, Wei J, Liu X. Alteration of histone acetylation pattern during long-term serum-free culture conditions of human fetal placental mesenchymal stem cells. PLoS ONE. 2015;10:e0117068.

156. Wang Y, Chen T, Yan H, Qi H, Deng C, Ye T, Zhou S, Li FR. Role of histone deacetylase inhibitors in the aging of human umbilical cord mesenchymal stem cells. J Cell Biochem. 2013;114:2231-9.

157. Di Bernardo G, Squillaro T, Dell'Aversana C, Miceli M, Cipollaro M, Cascino A, Altucci L, Galderisi U. Histone deacetylase inhibitors promote apoptosis and senescence in human mesenchymal stem cells. Stem Cells Dev. 2009;18:573-82.

158. Song M, Heo J, Chun J-Y, Bae HS, Kang JW, Kang H, Cho YM, Kim SW, Shin D-M, Choo M-S. The paracrine effects of mesenchymal stem cells stimulate the regeneration capacity of endogenous stem cells in the repair of a bladder-outlet-obstruction-induced overactive bladder. Stem Cells Dev. 2013;23:654-63.

159. Jing H, Liao L, Su X, Shuai Y, Zhang X, Deng Z, Jin Y. Declining histone acetyltransferase GCN5 represses BMSC-mediated angiogenesis during osteoporosis. FASEB J. 2017;31:4422-33.

160. Yuan Z, Bian Y, Ma X, Tang Z, Chen N, Shen M. LncRNA H19 knockdown in human amniotic mesenchymal stem cells suppresses angiogenesis by associating with EZH2 and activating VASH1. Stem Cells Dev. 2019;28:781-90.

161. Xie Q, Wang Z, Zhou H, Yu Z, Huang Y, Sun H, Bi X, Wang Y, Shi W, Gu P. The role of miR-135-modified adipose-derived mesenchymal stem cells in bone regeneration. Biomaterials. 2016;75:279-94.

162. Chen X, Zhang Y, Wang W, Liu Z, Meng J, Han Z. Mesenchymal stem cells modified with heme oxygenase- 1 have enhanced paracrine 
function and attenuate lipopolysaccharide-induced inflammatory and oxidative damage in pulmonary microvascular endothelial cells. Cell Physiol Biochem. 2018;49:101-22.

163. Uchida S, Hayakawa K, Ogata T, Tanaka S, Kataoka K, Itaka K. Treatment of spinal cord injury by an advanced cell transplantation technology using brain-derived neurotrophic factor-transfected mesenchymal stem cell spheroids. Biomaterials. 2016;109:1-11.

164. Kavanagh DP, Robinson J, Kalia N. Mesenchymal stem cell priming: finetuning adhesion and function. Stem Cell Rev Rep. 2014:10:587-99.

165. Kim K-W, Kim HJ, Kim B-M, Kwon Y-R, Kim H-R, Kim Y-J. Epigenetic modification of mesenchymal stromal cells enhances their suppressive effects on the Th17 responses of cells from rheumatoid arthritis patients. Stem Cell Res Ther. 2018;9:208.

166. Kang H, Kim K-H, Lim J, Kim Y-S, Heo J, Choi J, Jeong J, Kim Y, Kim SW, Oh Y-M. The therapeutic effects of human mesenchymal stem cells primed with sphingosine-1 phosphate on pulmonary artery hypertension. Stem Cells Dev. 2015;24:1658-71.

167. Lim J, Lee S, Ju H, Kim Y, Heo J, Lee H-Y, Choi K-C, Son J, Oh Y-M, Kim I-G. Valproic acid enforces the priming effect of sphingosine-1 phosphate on human mesenchymal stem cells. Int J Mol Med. 2017:40:739-47.

168. Xu L, Xing Q, Huang T, Zhou J, Liu T, Cui Y, Cheng T, Wang Y, Zhou X, Yang B. HDAC1 silence promotes neuroprotective effects of human umbilical cord-derived mesenchymal stem cells in a mouse model of traumatic brain injury via PI3K/AKT pathway. Front Cell Neurosci. 2018;12:498.
169. Lakshmaiah K, Jacob LA, Aparna S, Lokanatha D, Saldanha SC. Epigenetic therapy of cancer with histone deacetylase inhibitors. J Cancer Res Ther. 2014:10:469.

170. McCabe MT, Ott HM, Ganji G, Korenchuk S, Thompson C, Van Aller GS, Liu Y, Graves AP, Diaz E, LaFrance LV. EZH2 inhibition as a therapeutic strategy for lymphoma with EZH2-activating mutations. Nature. 2012;492:108.

171. Greiner D, Bonaldi T, Eskeland R, Roemer E, Imhof A. Identification of a specific inhibitor of the histone methyltransferase SU (VAR) 3-9. Nat Chem Biol. 2005;1:143.

172. Dekker FJ, Haisma HJ. Histone acetyl transferases as emerging drug targets. Drug Discov Today. 2009;14:942-8.

173. Pulecio J, Verma N, Mejía-Ramírez E, Huangfu D, Raya A. CRISPR/Cas9based engineering of the epigenome. Cell Stem Cell. 2017;21:431-47.

174. Patel S, Pongkulapa T, Yin PT, Pandian GN, Rathnam C, Bando T, Vaijayanthi T, Sugiyama H, Lee K-B. Integrating epigenetic modulators into nanoscript for enhanced chondrogenesis of stem cells. J Am Chem Soc. 2015;137:4598-601

\section{Publisher's Note}

Springer Nature remains neutral with regard to jurisdictional claims in published maps and institutional affiliations.
Ready to submit your research? Choose BMC and benefit from:

- fast, convenient online submission

- thorough peer review by experienced researchers in your field

- rapid publication on acceptance

- support for research data, including large and complex data types

- gold Open Access which fosters wider collaboration and increased citations

- maximum visibility for your research: over $100 \mathrm{M}$ website views per year

At BMC, research is always in progress.

Learn more biomedcentral.com/submissions 